\title{
Perioperative endoscopy of the whole small bowel in Crohn's disease
}

D Lescut, D Vanco, P Bonnière, $M$ Lecomte-Houcke, P Quandalle, A Wurtz, J F Colombel, J S Delmotte, J C Paris, A Cortot assessed preoperatively ( $x$ ray film and pull through) and during operation by the surgeon. The influence of the extra information provided by perioperative enteroscopy on the surgical treatment was also assessed.

\section{Patients and methods}

\section{PATIENTS}

Table I gives patient's details

Twenty patients with Crohn's disease were operated on (seven women, 13 men mean age 29 , range 18-50 years). The mean time between the first diagnosis of Crohn's disease and surgery was 4.5 (range 0-28) years. Crohn's disease was ileocolonic in 13, ileal in five, and colonic in two cases. Fourteen patients had surgery for a nonperforative form of Crohn's disease (11 stenosis, one bleeding ulceration, and two failure of medical treatment) and six for a perforative complication (five fistulae and one abscess) (Table II). Surgical procedures were an ileocolectomy (16 of 20 patients) or a small bowel or colonic resection (four of 20 patients).

TABLE I Clinical data for 20 patients who had a perioperative enteroscopy during surgery for Crohn's disease

\begin{tabular}{clllll}
\hline $\begin{array}{c}\text { Patient } \\
\text { No }\end{array}$ & Sex & $\begin{array}{l}\text { Age } \\
(y)\end{array}$ & $\begin{array}{l}\text { Extent } \\
\text { of } \\
\text { disease }\end{array}$ & POE & Surgical procedure \\
\hline 1 & M & 28 & IC & + & Ileocolectomy \\
2 & M & 39 & IC & - & Ileocolectomy \\
3 & F & 27 & IC & + & Right ileocolectomy \\
4 & M & 30 & IC & - & Right ileocolectomy \\
5 & F & 25 & IC & + & Ileocolectomy \\
6 & M & 19 & IC & + & Right ileocolectomy \\
7 & M & 28 & IC & + & Ileocolectomy \\
8 & M & 22 & SB & + & Ileal resection \\
9 & M & 49 & I & + & Right ileocolectomy \\
10 & M & 25 & C & - & Colectomy \\
11 & M & 27 & IC & - & Right ileocolectomy \\
12 & F & 26 & IC & + & Right ileocolectomy \\
13 & M & 30 & I & + & Right ileocolectomy \\
14 & F & 39 & IC & + & Right ileocolectomy \\
15 & F & 18 & IC & + & Right ileocolectomy \\
16 & M & 20 & IC & + & Right ileocolectomy \\
17 & M & 24 & I & - & Right ileocolectomy \\
18 & F & 50 & IC & - & Right ileocolectomy \\
19 & F & 39 & C & - & Colectomy \\
20 & M & 28 & I & + & Ileal resection \\
\hline
\end{tabular}

$\mathrm{IC}=$ Ileocolon; $\mathrm{I}=$ ileum; $\mathrm{C}=$ colon; $\mathrm{SB}=$ small bowel; $\mathrm{POE}+$ or $-=$ presence or absence of lesions at perioperative POE +or-
endoscopy.

TABLE II Surgical indication in 20 patients with Crohn's disease having complete perioperative enteroscopy

\begin{tabular}{lc}
\hline Surgical indication & No of patients \\
\hline Non-perforative forms: & 14 \\
Ulcerated stenosis & 7 \\
Non-ulcerated stenosis & 4 \\
Resistance to medical treatment & 2 \\
Bleeding lesions & 1 \\
Perforative forms: & 6 \\
Fistula & 5 \\
Abscess & 1 \\
\hline
\end{tabular}

Crohn's disease is a chronic condition that may whole digestive tract. Involvement of upper gastrointestinal tract and colon hich can detect small mucosal lesions. The involvement of the small bowel may be checked a small bowel pull through technique, except in its upper portion (jejunoscopy) or At surgery Crohn's disease lesions are searched or by a thorough inspection and palpation of the el by the surgeon. Few surgeo pull through technique with an inflated balloon nearch systematically for small bowel stenosis plete retrograde (to the angle of Treitz) perioperative enteroscopy is a procedure that could allow the detection of such stenosis and further mucosal lesions of Crohn's disease. The aim of this work was to compare in 20 patients operated on for Crohn's disease the pattern of small bowel involvement assessed by perioperative enteroscopy as compared with small bowel involvement

\author{
Centre Hospitalier \\ Régional et Faculté de \\ Cedex, France \\ Correspondence to: \\ D Lescut, Clinique des \\ Maladies de l'Appareil \\ Digestif, Hôpital Claude \\ Huriez, 1 Place de Verdun \\ CHR 59037 Lille Cedex, \\ France. \\ Accepted for publication \\ 17 September 1992 \\ l'Appareil Maladies de \\ D Lescut \\ $P$ Bonnière \\ J S Delmot \\ J C Paris \\ Service de Chirurgie \\ Aduite Ouest \\ Laboratoire d'Anatomie \\ Pathologique
}

. 


\section{Methods}

All perioperative endoscopies were performed in the surgical room by two endoscopists of our unit. Perioperative endoscopy was commenced after the surgeon had completed the intestinal resection (at $5 \mathrm{~cm}$ above the upper limit of macroscopic lesions). A colonoscope (Olympus) coated with a sterile light tissue was introduced through the distal opening of the small intestine. The endoscope was pushed up by the hands of the surgeon until its tip was at the angle of Treitz. A careful analysis and staging of the lesions were performed when the colonoscope was pulled through slowly all along the bowel. Endoscopic biopsy specimens were taken on macroscopic mucosal lesions and on mucosa facing the serosal lesions recognised by the surgeon. Systematic biopsy specimens were also taken on endoscopically normal mucosa every $20 \mathrm{~cm}$. For each patient 12 to 20 specimens were taken and analysed separately on serial sections that were stained with haematoxylin and eosin.

\section{Results}

The only complication occurred early in the study. This was a small perforation after a biopsy done with forceps with a central needle. This perforation was simply sutured and further samples were taken with forceps without a central needle. The mean duration of the hospital stay of the patients having had perioperative endoscopy during their surgical treatment was 13 days (identical to that of other patients operated on for Crohn's disease without perioperative endoscopy).

\section{ENDOSCOPIC FINDINGS}

Perioperative endoscopy was completed up to the angle of Treitz in all 20 patients and occupied between 30 and 40 minutes. The mean length of the small bowel explored by perioperative endoscopy was 265 (range 180-320) cm. In 13 of 20 cases endoscopic lesions were found (65\%). Table III gives the details. Mild lesions such as aphtoid ulcerations were the most frequent. More severe lesions such as deep ulcerations (two cases) or ulcerated stenosis (one case) were also found although they were less frequent. Lesions were distributed evenly along the small intestine, without predominance in the lower or upper part. In nine of 13 cases the endoscopist estimated the amount of diseased area as involving less than $50 \mathrm{~cm}$ of bowel and in four cases it was estimated as more than $50 \mathrm{~cm}$. In seven of 13 (54\%) patients perioperative endoscopy detected mucosal lesions proximal to the section margin when preoperative $x$ ray films had been normal.
In six of 13 cases (46\%) some lesions were detected by preoperative $x$ ray film but were underestimated in their extent. These 'ignored' lesions were always moderate as opposed to severe lesions which had always been diagnosed on $x$ ray film in other parts of the small bowel of these patients.

\section{HISTOLOGICAL RESULTS (TABLE IV)}

In all patients (with or without lesions) the most frequent abnormalities found with perioperative endoscopy were an infiltration with predominantly eosinophilic polymorphs (16) and a nonspecific infiltration with an increase in neutrophylic polymorphs, lymphocytes, plasma cells, and lamina propria macrophages (17). In patients with lesions at perioperative endoscopy, the inflammatory lesions were almost equally distributed in biopsy specimens taken from macroscopically diseased and normal mucosa. Conversely typical granulomas were obtained in three patients with lesions at perioperative endoscopy on biopsies of abnormal mucosa, and only in one having a normal perioperative endoscopy. As a whole, the group of patients without lesions at perioperative endoscopy had less histological abnormalities than those with lesions, although infiltration with predominantly eosinophilic polymorphs and non-specific changes were found on seven occasions.

\section{MODIFICATION OF SURGICAL TREATMENT}

Perioperative endoscopy significantly modified the surgical treatment in two of 20 patients. In the first case perioperative endoscopy revealed an ulcerated stenosis (short and mildly narrowed) that had been previously ignored in both preoperative and perioperative investigations. This stenosis was resected. In the second case, perioperative endoscopy allowed us to identify the origin of a small bowel bleeding which had not been identified perioperatively by the surgeon. It was a badly ulcerated portion of small intestine that was consequently resected.

\section{Discussion}

Endoscopic inspection of the small bowel is increasingly used in the diagnosis of Crohn's disease both before and after surgical resection..$^{34}$ Perioperative ileoscopy has recently been reported although only dealing with $30 \mathrm{~cm}$ of the residual neoterminal ileum. ${ }^{5}$ Our report is the first one of a complete systematic inspection of the small bowel far from the resected area. Our main finding was that endoscopic lesions were present in $65 \%$ of patients operated on for
TABLE III Endoscopic
lesions found at complet perioperative enteroscopy in 13 patients out of a total of 20 patients having surgery 20 patients having
for Crohn's disease

\begin{tabular}{ll}
\hline Endoscopic lesions & $\begin{array}{l}\text { No of } \\
\text { patients }\end{array}$ \\
\hline Aphtoïd ulcerations & 10 \\
Superficial ulcerations & 7 \\
Mucosal oedema & 3 \\
Non-ulcerated stenosis & 3 \\
Erythema & 2 \\
Pseudopolyps & 2 \\
Deep ulcerations & 2 \\
Ulcerated stenosis & 1 \\
\hline
\end{tabular}

TABLE IV Histological findings from biopsies taken during complete perioperative enteroscopy (POE) in 20 patients having surgery for Crohn's disease

\begin{tabular}{|c|c|c|c|c|c|c|}
\hline & Granulomas & $P N E$ & $\begin{array}{l}\text { Superficial } \\
\text { erosions }\end{array}$ & $\begin{array}{l}\text { Lymphoid } \\
\text { aggregation }\end{array}$ & $\begin{array}{l}\text { Non-specific } \\
\text { infiltration }\end{array}$ & Normal \\
\hline \multicolumn{7}{|l|}{ Patients with lesions at $\operatorname{POE}(n=13)$ : } \\
\hline Biopsies of diseased mucosa & 3 & 8 & 2 & 1 & 7 & 2 \\
\hline \multirow{2}{*}{\multicolumn{7}{|c|}{ Patients without lesions at POE $(n=7)$ : }} \\
\hline & & & & & & \\
\hline Biopsies of normal mucosa & 1 & 3 & 0 & 0 & 4 & 5 \\
\hline
\end{tabular}


Crohn's disease and that these lesions were evenly distributed in all portions of the small intestine.

Endoscopic lesions of the small bowel discovered at perioperative endoscopy were superficial and similar to those described in colonic Crohn's disease. ${ }^{6-8}$ Some findings could, however, be linked to the specific conditions of perioperative endoscopy: (1) some endoscopic lesions might be due to an agglutination of bowel loops facing bowel portions involved by Crohn's disease causing oedema, erythema, and swollen mucosa; (2) some substenoses were revealed only during insufflation and had been previously ignored by pre and perioperative investigations; (3) some tiny mucosal lesions were noticed by the surgeon on the serosal surface of the small bowel because of the transillumination of the endoscope and the surgeon informed the endoscopist. Some other lesions are difficult to interpret: ulcerations and petechiae could have been produced from the blind progression of the endoscope during the initial part of the procedure. Similarly erythema, mucosal oedema, and other lesions contiguous to intestinal stenosis might not be specific. Therefore, perioperative endoscopy in Crohn's disease must be performed by an experienced endoscopist used to this specific technique and able to minimise those problems.

Perioperative endoscopy is so far not a routine procedure during surgery for Crohn's disease. Some groups detect silent stenosis by a pull through technique with an inflated balloon. ${ }^{12}$ Some anecdotal reports of perioperative endoscopy have been published ${ }^{9}$ and some reports mention numerous complications due to infection. ${ }^{3}$ As discussed previously, our only complication, was a perforation ascribed to the use of forceps with a centre needle during biopsy. The duration of the surgical procedure was not lengthened, and the hospital stay of patients who had a perioperative endoscopy was identical to that of other Crohn's disease patients who had surgery.

In our experience, the practical value of perioperative endoscopy for the management of patients was limited. Although two of 20 patients had their surgical treatment modified on the basis of perioperative endoscopy data, it was not modified in the 18 remaining cases.

Biopsy specimens did not provide any further histological evidence for the diagnosis of Crohn's disease in our patients. As previously pointed out $^{4}$ the results obtained by perioperative endoscopy and histological examinations of endoscopic biopsies correlated reasonably well. A granuloma was found in four patients, three times on a macroscopically diseased mucosa. The most frequent histological features were nonspecific changes whether or not biopsy specimens were taken from endoscopically normal or diseased mucosa. There was, however, a more pronounced tendency toward a higher frequency of eosinophilic infiltration and superficial erosions in biopsies of abnormal compared with normal mucosa. Infiltration with predominantly eosinophilic polymorphs has already been referred to in several studies. ${ }^{40-12}$ Rutgeerts et al found such an eosinophilic infiltrate in $25 \%$ of the specimens obtained in early ileal lesions after ileocolonic anastomoses and pointed out that in more severe lesions the infiltrate was more mixed. ${ }^{4}$ Lymphoid aggregates were difficult to interprete because they were found mainly in patients operated on for symptomatic ileal stenosis and subocclusion may result in a nonspecific inflammation. ${ }^{13-15}$ Similarly surgical manipulation of the intestinal loops as well as the passage of the endoscope may lead to perivascular inflammatory infiltrates and even blood suffusions. ${ }^{16} 17$

In our experience the practical interest in perioperative endoscopy was limited. It did not provide significant help either in the diagnosis or the surgical management of patients operated on for Crohn's disease. It may be a valid tool, however, in studies designed to improve knowledge of the natural history of silent lesions of Crohn's disease and their potential relation with subsequent clinical relapses. As a first step we have carried out a retrospective study in another group of 34 patients and did not find any relation between the presence of small bowel lesions at perioperative endoscopy and endoscopic asymptomatic recurrences. ${ }^{18} \mathrm{~A}$ prospective study is in progress.

1 Alexander-Williams J, Haynes I. Conservative operations for Crohn's disease of the small bowel. World $\mathcal{F}$ Surg 1985; 9: 945-51.

2 Alexander-Williams J, Allan A, Morel P, Hawker P, Dykes P, $\mathrm{O}$ 'Connor $\mathrm{H}$. The therapeutic dilatation of enteric strictures due to Crohn's disease. Ann R Coll Surg Engl 1986; 68: 95-7. 3 Tytgat GNJ,Mulder CJJ, Brummelkamp WH. Endoscopic lesions in Crohn's disease early after ileocecal resection. Endoscopy 1988; 20: 260-2.

4 Rutgeerts P, Geboes K, Vantrappen G, Kerremans R, Coenegrachts JL, Coremans G. Natural history of recurrent Crohn's disease at the ileocolonic anastomosis after curative surgery. Gut 1984; 25: 665-72.

5 Olaison G, Smedh K, Sjodahl R. Natural course of Crohn's disease after ileocolic resection: endoscopically visualised ileal ulcers preceeding symptoms. Gut 1992; 33: 331-5.

6 Groupe d'Etudes Therapeutiques des Affections Inflammatoires du Tube Digestif (Getaid) presented by Mary JY, Modigliani R. Development and validation of an endoscopic index of the severity for Crohn's disease. A prospective index of the severity for Crohn's dise

7 Modigliani R, Mary JY (Getaid) Reproductibility of colonoscopic findings in Crohn's disease. Dig Dis Sci 1987; 32: 1370-9.

8 Waye JD. Endoscopy in inflammatory bowel disease. Clinical Gastroenterology 1980; 9: 279-96.

9 Nakatake K. Operative intestinal fiberscopic findings and recurrences following surgery in Crohn's disease. Fukuoka Igaku Zasshi 1984; 75: 366-79.

10 Hallgren R, Colombel JF, Dahl R, Fredens K, Kruse A, Jacobsen S, et al. Neutrophil and eosinophil involvement of the small bowel in patient with celiac disease and Crohn's disease. Am $\mathcal{F}$ Med 1989; 86: 56-64.

11 Morson BC, Dawson IMP. Inflammatory disorders. In: Gastrointestinal pathology. Oxford: Blackwell Sci Publications, 1990: 267-76.

12 Willoughby CP, Piris J, Truelove SC. Tissue eosinophils in ulcerative colitis. Scand $\mathcal{F}$ Gastroenterol 1979; 14: 395-9.

13 Cooper JC, Williams NS. The influence of microscopic disease at the margin of resection on recurrence rates in Crohn's disease. Ann R Coll Surg Engl 1986; 68: 23-6.

14 Heuman R, Boeryd B, Bolin T, Sjodahl R. The influence of disease at the margin of resection on the outcome of Crohn's diseaste Br F Surg 1983; 70: 519-21.

15 Wolff BG, Beart RW, Frydenberg HB, Weiland LH, Agre MV, Ilstrup DM. The importance of disease-free margins in resections for Crohn's disease. Dis Colon Rectum 1983; 26 : resections

16 Hamilton SR, Reese J, Pennington L, Boitnott JK, Bayless $T M$, Cameron JL. The role of resection margin frozen section in the surgical management of Crohn's disease. Sur Gynecol Obstet 1985; 160: 57-62.

17 Pennington L, Hamilton SR, Bayless TM, Cameron JL. Surgical management of Crohn's diseases. Influence of disease at margin of resection. Ann Surg 1980; 192: 311-8.

18 Lescut D, Vanco D, Colombel JF, Bonniere P, Quandalle P Lecomte-Houcke $M$, et al. Influence des lésions endoscopiques d'amont sur les lésions endoscopiques anastomotiques au cours de la maladie de Crohn [Ábstract]. Gastroenterol Clin Biol 1990; 14: A20. 